\title{
Leadership and Group Formation in High-Rise Building Evacuations
}

\author{
B. K. JONES \\ Division of Building Research \\ National Research Council Canada
}

J. ANN HEWITT

dh Access Research Associates, Ottawa, Canada

\section{ABSTRACT}

This study addresses group formation and leadership during the evacuation of a high-rise office building due to fire. Rather than focussing on the psychological parameters of individual evacuee behaviour, the authors concentrate on the social context and organizational characteristics of the occupancy within which decisions about evacuation strategy, group formation and questions of leadership are made. A distinction is drawn between "emergent" (situational) and "imposed" (authoritative) leaders and between the processes of status emergence (achievement of influence) and status maintenance (retention of influence). Both leadership and group formation can be viewed not only in terms of psychological processes but also as the interaction between the normal organizational structure and the roles people assume and play within their group.

\section{INTRODUCTION}

This paper represents an analysis of the impressions, interpretations and actions of a number of people who were required to evacuate a twenty-seven-storey office building because of fire. Two researchers from the Division of Building Research, National Research Council of Canada, conducted in-depth interviews with forty of the participants in the evacuation as well as with ten firefighters who came into contact with evacuees during the course of their duties. These interviews, including the respondents' descriptions of the event and questions posed by the interviewers for clarification, were tape recorded and subsequently transcribed.

The transcripts were analyzed on the basis of a number of categortes including communication (formal, intragroup and intergroup), fire experience and training, movement through smoke and wayfinding, group formation, and leadership. The method of analysis used in this study draws on a number of sources including Breaux (1976), Canter (1980) and Sime (1980). This paper reports on a single issue or category of analysis: leadership and group formation. A more detailed account of the incident is currently in preparation.

Sime (1983) takes the position that in order to maximize an occupant's ability to escape, the building designer must consider the important psychological aspects of people's response to a fire. The authors would go a step further by suggesting that, in addition to the psychological aspects, one 
must take into account the social and organizational characteristics of the occupancy, including what a person knows (or believes) of the situation, whether the person is alone or part of a group, the normal roles that people hold within the occupancy, and the organizational structure or framework. One factor that appears to be related to the chosen evacuation strategy of an occupant is the presence of leadership and the form which that leadership takes.

A great deal of the social psychological research on the question of leadership and its effect on group decision-making has been carried out in laboratory settings. These experiments have tended to focus upon the psychological traits or personality characteristics of individual group members and the context was considered, for the most part, only as it provided a framework for addressing these questions (Shaw, 1973). Current approaches, however, place more emphasis on situational variables such as the internal structure of group organization, the established role relationships within the group, and the broader organizational framework within which group formation and leadership occur. These issues are considered crucial to any attempt at understanding how groups cope with an external problem or threat. Hollander (1971, p. 496), for example, holds that "leaders are made by circumstance" and draws a distinction between "emergent" (situational) and "imposed"

(authoritative) leaders. Imposed leadership is determined by authority or by virtue of a person's position in the organizational hierarchy, whereas the situational approach conceives of leadership in terms of the function to be performed rather than in terms of the persisting traits of the leader. Hollander also hypothesized that the relationships by which leadership is produced or retained within groups may be further distinguished by:
"... studying the interrelated processes of status emergence, concerning factors at work in the achievement of influence, and status maintenance, covering those which allow the retention of influence [author's emphasis].... The retention of leadership necessarily depends somewhat upon others' perceptions of competence and effectiveness" (Hollander, 1971, p. 498).

Leadership in most organizations is of the imposed type, where group membership and structure, as well as the task requirements of leaders, are set. One of the ains of this study is to look at how this system operates under conditions of threat, when the structure of the established emergency plan is absent. This would entail examining not only the performance of groups and their leaders in the incident but also the perceived competence of the leaders in terms of the specific tasks of the group at the time and the adherence of the individual group members to the pre-emergency organizational procedures.

Although the following case studies do not exhaust the 1ist of evacuees from the building, they do represent distinct leadership situations. The case studies include a situation where leadership was imposed and status maintained; one in which leadership was not retained and new leadership and status emerged; and finally one in which two imposed leaders directed a group's actions until a delay in egress led to a split in the group and in the leadership. This analysis is based upon the accounts of participants. It is not suggested that any actors had or did not have "leadership potential", an approach which would necessitate a discussion of personality traits. Instead the approach taken in this paper is centred on the fire situation itself and the strategy for evacuation selected by leaders and groups. 
The building in which the fire took place is located in Ottawa, Canada. It consists of a twenty-seven-storey central core office tower, a nine-storey above-ground parking garage, and a ground level shopping mall. At the time of the fire, the building was approximately ten years old, with a rentable floor area of approximately $130,000 \mathrm{~m}^{2}$. The bullding has two separate and separated banks of elevators, one bank serving floors 1 to 14 , the other serving floors 15 to 27, and four exit stairwe11s located at each end of the core. The office space is a typical open plan design with acoustical screens dispersed throughout the floor areas.

The on-site fire protection facilities consist of a fire alarm system connected to the central station of an off-premises alarm company, a klaxon alarm horn system and a 'Iive' voice communication system with speakers on all floors and in the stairwells. Manual pull stations and two emergency telephones on each floor are connected to the fire control room on the building's main level. The building is equipped with a sprinkler system, covering the entire basement and main plaza levels as well as the waste storage rooms and garbage chute on each floor, heat detectors in the service rooms, smoke detectors in the return air ducts, a standpipe and hose system, portable fire extinguishers, and a diesel generator to provide emergency power and lighting throughout the building.

\section{FIRE INCIDENT}

At approximate1y 21:00 hours on a Wednesday in late November a smoke alarm on the third floor sounded a general alarm throughout the building and alerted the Fire Department. The fire alarm sounded for one full minute, although a number of occupants raised questions as to how long the alarm actually did ring. At the end of this period, the alarm was automatically silenced and a building security officer, using the voice communication system, notified the occupants that the cause of the alarm was being investigated and that they should remain at their work stations and await further instructions. At almost the same time as the voice announcement was made, a number of occupants on the fire floor (third) and on the upper floors (fifteenth to twenty-third) reported either seeing or smeling smoke, thus becoming aware that a fire actually did exist. A number of these people who saw or smelled the smoke, particularly those on the upper floors, decided to ignore the announcement to await further instructions and proceeded to evacuate the building via the stalrwells and elevators. Other occupants followed the instructions given over the volce communication system and waited for further instructions.

Approximately five to ten minutes after the original standby message, another announcement was made over the commuication system instructing all occupants to evacuate the building. A number of the evacuees who were interviewed were vague concerning the length of time between the two announcements, with some insisting that there was an interim announcement telling the third floor occupants to evacuate. With this general notice to evacuate, those who had waited proceeded to leave the building via the stairs and elevators. By this time, however, many of the people from the upper floors who had evacuated at the first sign of smoke, were already coming back up the stairs, having found the smoke in the stairwe1ls too dense or too irritating (in their opinion) to continue. The evacuees who used the elevators encountered no difficulty in reaching the main plaza level. Many of those using the stairwells had to make several attempts, due to smoke 
conditions, before they reached the ground floor. One group of government employees from floors 20 to 23 took forty to fifty minutes to reach the main plaza level, utilizing two different stairwells and ascending and descending some sixty flights of stairs in the process.

The number of people in the building at the time of the fire is open to question, although the office of the Dominion Fire Commissioner (now the Fire Commissioner of Canada) estimated it to be 128 . Of this number, thirty were federal employees, thirty were employees of a large private company, sixty-four were employees of the building's property management firm (mostly cleaning staff under contract), and four were employees of a law firm. The Ottawa Fire Department received the alarm at 21:00 and arrived at the building approximately two minutes later. The fire was brought under control by about 23:42, with the ali clear given at 03:11. There were no fatalities but twenty-one of the evacuees and six firefighters were taken to hospital and treated for smoke inhalation. A11 but one were released the same evening; the remaining person was admitted overnight but was released from hospital the following morning.

Case No. 1: Printing Unit, 23rd floor

Description. A printing unit on the twenty-third floor constituted a separate and well defined group. It consisted of six people: two men, one of whom was a supervisor, and four women. Most of the group members, except the supervisor, reported hearing the alarm. He was working in an enclosed office on the shop floor but due to the notse of the machinery he remained unaware that the alarm was ringing. The other man, who served as assistant foreman, also had difficulty hearing the alarm. All of the women except one interpreted the alarm as false and continued to work. One woman stopped what she was doing and waited for the voice announcement which she believed was coming. No such announcement was made until the group had already reached the main lobby.

The group continued working until one of the women mentioned to her co-workers that she thought she could smell smoke. Upon looking into the corridor the three women could see smoke pouring from the freight elevator shaft and one of them informed the supervisor. When he saw the smoke he told the women to gather their personal belongings and to wait for him in the elevator lobby. While he shut down the machinery and locked the shop area, the assistant foreman went to inform some other people on a different part of the floor that the alarm signalled a real fire. Both men rejoined the waiting group and took the same elevator, reaching the main lobby on the ground floor without mishap.

Discussion. The leadership pattern in this group represents an explicit example of the 'imposed' type, that is, leadership by virtue of position within the organizational framework. The members of the group abided by the supervisor's decisions, although a majority of them later expressed reservations about the course of action he selected. Several women reported thinking that they should not use an elevator as a means of evacuation, but no one voiced this concern during the egress. During the interview, the supervisor stated that his decision to take the elevator was a "quick one" and that he "didn't think too much about it". Most members of the group had particlpated in at least one fire drill in this or some other building. They characterized the training they received, however, as consisting of gathering in the corridor and following the instructions of the officer in charge. The supervisor, on the other hand, had never particpated in a drill nor had he ever read anything distributed by the building's fire safety committee about 
what to do in the event of a fire. Moreover, he had never been told what his duties as a supervisor were in an emergency which occurred after normal working hours when the structure imposed by the emergency plan was absent, even though the printing unit often worked late. This lack of training is evidenced by the fact that using the stairs or the emergency telephones did not occur to him.

However, the supervisor's leadership of the group remained intact and his instructions were followed although the proper procedures were known by some group members. For example, while waiting for the assistant foreman to return from warning other floor occupants, several women became nervous and began shouting for him to hurry. One woman was especially angry at the delay ("I could have killed the guy") and urged the group to leave him behind. This suggestion was ruled out by the supervisor and they continued to wait for his return. In general, the leadership pattern apparent in this group was of the imposed type, that is, imposed by the organizational structure. A new leader did not emerge from the membership as a result of either perceived superior. knowledge or force of personality. In the interviews, several people said that during the fire they considered some of his instructions with trepidation. He maintained his status as leader nevertheless and they accepted his directions, or as one woman stated: "I just did what the boss told me".

Case No. 2: Purchasing/Stores; Mail Room, 15th floor

Description. Five people were working in two separate rooms on the fifteenth floor at the time of the fire: two men in stores and two men and a woman in the mailroom. Everyone reported hearing the alarm when it first sounded. The male supervisor from the mailroom went into the corridor to listen for the announcement that would come over the public address system. When he saw smoke escaping from the freight elevator shaft, he shouted a warning to the two men in the other room and returned to his office and told his staff to get ready to leave. One of the men from the purchasing/stores unit, however, had already been in the corridor and smelled smoke. He returned to tell his co-worker about it and said he was leaving the building immediately. As he was gathering his belongings, the other man went to check the corridor for himself and had just noticed the smoke when he heard the supervisor's warning. The five people joined together and decided to evacuate via the nearest exit stalrs.

They started their descent, but upon reaching the twelfth floor they could see smoke coming up the stairwell towards them. By the time they reached the fifth floor the smoke was quite thick and irritating to the eyes and throat. At the fourth floor they found the smoke too dense to continue and decided to change to another stairwe11. The group began ascending the stairs, trying to find an unlocked door from the stairwell to the office space. They found a door open on the ninth floor, crossed the office area, and entered the stairwell on the opposite side of the building. Here they met a group of women from the cleaning staff and together they began to walk down the stairs. Within a floor or two they encountered smoke as thick as in the other stairwel1. Returning to the ninth floor, they entered the office area and argued about what to do next.

The supervisor, supported by the man from the mailroom and one of the men from purchasing/stores, wanted to go up the stairs to the roof and find fresh air. The other man from stores tried to convince them to try to make it down the stairs. He argued that if they went back down they would have only nine floors to go and that, as the smoke was rising, the higher they climbed the 
more smoke they would eventually have to go through. The three men were adamant about trying for the roof; the female members of the group did not appear to take part in the debate. Here the group split apart. One group, consisting of three men, left and continued up the stairs toward the roof. In their ascent they encountered another group and their subsequent actions are described in case number three. The other group consisted of one man from the purchasing/store room, the woman from the mailroom and the female cleaning staff. He led them to a washroom where they wet their sweaters, and covering their faces with them, proceeded down the stairs to the main lobby without much difficulty.

Discussion. Both imposed and emergent leadership were evident in this group as well as status maintenance and status emergence. From the beginning, the supervisor displayed characteristics of imposed leadership. It was he who checked the corridor, alerted the two men in the purchasing/store room, told the two people in his office that it was time to leave and locked the office after them. He led the group to the stairwell and although the two men from the other office did not come under him in the organizational structure they seemed willing to follow his lead. When the group reached the fourth floor it was apparently the supervisor who felt most strongly that the smoke was impassable and that they should change stairwells. The rest followed him as he went back up the stairs trying to find an unlocked door. The man from the purchasing/store room, who later left the group, reported thinking that if the stairwell was impassable the person on the public address system would have mentioned it. Nevertheless, he went along with the supervisor, who maintained his leadership status. After they had come back up the second stairwe11, however, the leadership pattern underwent some change. The supervisor, supported by two of the men, stated that the group should try for the roof. The other man from purchasing/stores argued that this course of action was foolish and tried to convince the group to make for the ground floor.

Although this man displayed a fair degree of knowledge about the properties of fire and smoke movement, the supervisor and the two men disregarded his advice. He, in turn, rejected the decision by the supervisor. In the interview he stated that he was willing to go along with the group and follow the lead of the supervisor as long as their actions corresponded with what he thought they should do. When the supervisor advocated a course of action which he believed to be wrong, he withdrew his support. When the three men left for the roof the women members remained with this man. One of the women said he seemed to make sense and she thought he knew what he was doing. The man later stated that he was nervous but that: "as long as I'm involved with someone else, I don't think about myself". He also said that he would not accept a post as a fire warden because he doesn't want to feel obligated to help other people. Moreover, people lack respect for him because of the low status position he holds and consequently they wouldn't follow his instructions.

Case No. 3: Communications Unit - 23rd floor

Description. At the time of the fire alarm, fourteen people were working on the twenty-third floor. This case study pertains to seven of those people (two men and five women); the remainder did not form part of this particular group but left the building on their own as part of other groups. Of these seven people, five had been working together in one large office and two had been working in a separate area. In this group, the two men were senior to the five women in the organizational hierarchy and were supervising the evening work. After hearing the alarm, one of the men tried unsuccessfully to reach the fire control centre via the emergency telephone. Both men instructed the women to lock up and prepare to evacuate, while they checked 
the adjacent floors to ensure that no one remained. The group then proceeded down the stairwe11. At the fifteenth floor, they encountered three men coming up the stairs, who informed them that the stairwell was impassable at the lower levels due to smoke. The group, now consisting of ten members, took refuge on the fifteenth floor until increasing smoke levels led to a decision to proceed to the roof. On their ascent, they met another male evacuee, who joined the group in its climb. When this group of eleven people reached the twenty-seventh floor, one of the senfor male employees and another male went up the short flight of stairs to the roof door. They found this door locked and shouted the information to those waiting below.

At this point, the group divided, and three of the men, who had not been part of the original group, descended on their own. The remaining eight people (three men and five women) returned to the twenty-seventh floor. One of the senior male employees provided the group with wet paper towels from the washroom. The group then split for a final time; one male accompanied by three females started down the stairs. The others remained on the twenty-seventh floor for a short period of time and then proceeded down the stairs themselves. They became the last occupants to leave the building, having taken some fifty minutes to do so.

Discussion. This situation presents a good example of imposed leadership. Both senior male employees influenced the egress strategy adopted by the group. Both were involved in informing the women working under their supervision to leave the building and at various times the two men attempted to contact the security personnel on the ground floor via the emergency telephones.

Quite clearly, the men perceived themselves to be the decision-makers, and this self-percepton was reinforced by the women members of the group. With few exceptions, group members reported that decisions on egress strategy were made by the male supevisors. The two leaders described not only their choices but also their decision-making role as "natural"; stressing their sense of responsibility for those working under them. Until the group reached the top floor, decisions appear to have been made jointly between these two men. The group followed their directions or, as one leader stated: "They did what we told them". Group members described the two males as knowledgeable, 'Level-headed' and calm and stated that they simply followed instructions.

The first key decision vis-a-vis the egress strategy was to accept the information given to them by the three men they encountered on the fifteenth floor. As the group was already encountering smoke in the stairwe11, both men considered it reasonable that descent would not be possible. In choosing to stop descent, they retained their status.

The second key decision was to proceed to the roof. Again, this was seen as an effective solution by group members in genera1. When this solution proved untenable, the leadership split. If leadership is viewed as that behaviour which best helps a group attain its goals, then in this case the leadership had falled, and the solidarity of the group dissipated. Ultimately, supervisors and their immediate staff exited the building together. Until the roof door was found to be locked, the women had been willing to follow either or both of the men. Following the failed attempt to open the roof door, these women reformed according to their normal organizational relationships. In their accounts of the group breakup, both the women and the male leaders expressed some confusion as to exactly why the group had split. Some suggested that it seemed more reasonable to descend in smaller groups; others felt that there wasn't a reason to wait any longer. At 
this point, leadership with respect to evacuation strategy had become irrelevant. There was no decision to be made, for the only remaining option or solution was descent. Not surprisingly, people descended with those with whom they were most familiar.

Case No. 4: Private Corporation, floors 2 to 12

Description. There were approximately twenty-four employees (ten female and fourteen male) of this company distributed over eleven floors at the time of the fire. The majority of these individuals were working alone and, apart from those nearest the fire floor, most people did not begin to evacuate until the general order was broadcast over the public address system. The stairs were the chosen means of egress for a11 of the occupants and although individuals may have encountered other people in the stairwells, it seems, from the interviews, that they considered this to be due to circumstance rather than choice. In other words, the occupants did not seek to form groups even when a number of individuals were working within sight and hearing of one another. For the most part, each person decided on which evacuation strategy to follow and acted upon this decision without consultation. Consequently, neither imposed or emergent leadership nor issues of status maintenance or emergence appeared to play a significant role in the evacuation of these occupants.

Discussion. A number of reasons may account for the lack of group formation and the non-emergence of leadership. For example, the majority of individuals who were working after regular office hours occupied positions at the middle management level in the organization's hierarchy. Most of their work was normally carried out on an individual basis, such as computer programming and analysis, systems or engineering design. In other words, they were used to making decisions on their own without consultation and many held supervisory posts in their own right. A second reason could relate to the fire safety training they had received. In addition to participating in the drills and exercises given by the building management company and the office of the Fire Commissioner of Canada, the corporation provided extra training in the form of audio-visual presentation and question and answer sessions. Although the employees of the private firm, like the federal government employees on the upper floors, stated that the training they had recelved did not prepare them for the "real thing", the former individuals, on the whole, took the more effective action. In the interviews, the corporation's employees consistently displayed a better grasp of the physical properties of fire and sound evacuation and safety practices. For instance, unlike a number of people from the upper floors, they did not assume that the fire was in the stairwel1 when they encountered smoke during their descent of the stairs, nor did they confuse the concepts of 'fire proof' and 'fire resistant'. In addition, they knew why the elevator was not an advisable method for evacuation during a fire. These people had no reason to form groups or to seek leaders in order to decide on the best course of action. They knew what to do and it was simply a matter of getting on with it.

\section{CONCLUSION}

In recent years, research carried out in the field of human behaviour and fire has indicated that numerous fire safety plans and strategies are often based on unsubstantiated assumptions about human and organizational response to emergencies or are predicated upon the belief that evacuation is a relatively simple process largely controlled by alarms, exit facilities and training programmes. In point of fact, research has demonstrated that 
behaviour in fire is far more complex than many such assumptions would suggest (see Stahl and Archea, 1977; Canter, 1980; Pauls and Jones, 1980). Sufficient evidence exists to suggest that not only are the psychological parameters important but also the social and organizational characteristics of the occupancy, including its organizational structure or framework and the normal roles that people hold within the organization.

The present report focuses on two of these organizational issues - group formation and leadership - and seeks to examine these phenomena in relation to the context or situation within which they emerge. Specifically, it looked at the notions of emergent (situational) and imposed (authoritative) leadership as well as the processes of status emergence (achievement of influence) and. status maintenance (retention of influence). The data seem to indicate that the presence of leadership and the form that it takes do affect the evacuation strategy adopted by a particular group. For the most part, the leadership of the groups studied corresponded to the roles assigned by the organization. In other words, the influence on group actions exercised by certain individuals was strongly related to the position these people occuped in the organizational hierarchy. Evidence of this is provided by the behaviour of group members who accepted the legitimacy of this arrangement, relinquished decision- making to these individuals and generally followed their directions despite later voicing opinions that some of the decisions made were not the most appropriate ones.

There were exceptions however. In one instance, an imposed leader failed to retain his influence over part of the group he was directing and a new leader emerged. The split that developed was apparently influenced by the group's perception of their respective competence and effectiveness. It seems that people are willing to go along with imposed or authoritative leadership only so far. If the proposed action is contrary to some strongly held opinions or contradicts some 'factual' information held by group members, or if the course of action chosen by the leader results in a situation where people perceive themselves to be more at risk than before, then the tenure of the existing leader may be challenged.

The data also indicate that both leadership and group formation are related to the fire training people receive and the normal roles they occupy in the organizational structure. The amount of knowledge occupants believed they possessed about what to do in a fire appeared to be an important element. Those who characterized their training as inadequate or their knowledge of fire as meagre were usually the people who sought consultation with others as to how to interpret the situation and the proper course of acton to follow. They also tended to rely on leaders, either imposed or emergent, for guidance. Unfortunately, many of the leaders in this incident did not possess any better knowledge of the proper course of action than those who sought their advice and consequently led the groups into situations that increased their risk.

One group of the study population, however, did not seek consultation or attempt collective action but acted, more or less, on an individual basis. In addition to occupying relatively higher status positions and having no one under their charge at the time of the incident, these individuals had the benefit of the most comprehensive fire training programme given to the building's occupants. The fact that the fire occurred when the emergency plan was not in operation made no difference to these occupants, for they knew what to expect and were prepared for any eventuality. These findings are in accord with what Swartz (1979) discovered in his study of the Beverly Hills Supper Club fire, where people retained the same general roles they had before the fire. In that incident, staff members took care of patrons at the tables, 
rooms and stations to which they were assigned; patrons looked to the staff for guidance. This led Swartz (1979, p. 73) to recommend that "fire safety plans... should examine the roles that people normally play and not seek to prescribe emergency actions that are contrary to these roles". Given the tendency of occupants to follow the directions of their immediate supervisor, it would appear crucial to ensure that these people recelved sufficient training to adequately fulfil this leadership role, especially when the structure of the emergency plan is absent. Moreover, even when the plan is in operation, assigning the task of floor fire warden to employees who occupy low status positions in the organization's hierarchy, a common enough practice, may create conflict or uncertainty among the occupants by pitting two imposed leaders against each another.

Normal organizational and occupancy structures are important in the behaviour of building occupants in a fire situation in general, and specifically leadership and group formation are strongly influenced by the organizational and situational contexts. The data upon which these conclusions are based, however, were derived from a single incident and: further investigation of these phenomena would be well justified.

This paper is a contribution of the Division of Bullding Research, National Research Council Canada.

\section{REFERENCES}

Breaux, J., Canter, D. and Sime, J.: "Psychological Aspects of Behaviour in Fire Situations," International Fire Protection Seminar (5th), Vol. 2, Karlsruhe, West Germany. Vereinigungzur Forderung des Deutschen Brandschutzes e.v., 1976.

Canter, D. (ed.): Fires and Human Behaviour, John Wiley and Sons, London/New York, 1980 .

Hollander, E.P. (ed.): Current Perspectives in Social Psychology, 3rd. ed., Oxford University Press, London/New York, 1971.

Pauls, J.L. and Jones, B.K.: "Research in Human Behaviour," Fire Journal, $73: 3,35-41,1980$.

Shaw, M.: Group Dynamics: The Psychology of Sma11 Group Behaviour, 2nd ed., McGraw-Hill, New York/Toronto, 1976.

Sime, J.D.: "The Concept of Panic," in Fires and Human Behaviour, ed. D. Canter, John Wiley and Sons, London/New York, 1980.

Sime, J.D.: "Affiliative Behaviour During Escape to Building Exits," Journal of Environmental Psychology, 3:1, 21-41, 1983.

Stah1, F. and Archae, J.: "An Assessment of the Technical Literature on Emergency Egress for Bulldings," NBS Report NBSIR77-1313, Center for Building Technology, Nationa1 Bureau of Standards, U.S. Dept. of Commerce, Washington, D.C., October, 1977.

Swartz, J.A.: "Human Behaviour in the Beverly Hills Fire," Fire Journal, 73: $3,1979$. 